\title{
FACTORS MODERATING ASYMMETRIC INTER-TIER COMPETITION: A CONCEPTUAL EXAMINATION USING PRICE-QUALITY TRADEOFF FRAMEWORK
}

\author{
K. Sivakumar, Lehigh University, USA
}

\begin{abstract}
Much existing research has demonstrated the superiority of high-tier brands over low-tier brands in benefitting from price competition between the two tiers. This research expands our knowledge by examining the role of factors moderating this asymmetry in inter-tier competition. Using the conceptualization of price-quality tradeoffs from existing research, we derive several research propositions that explicate how these moderating factors define the boundary conditions of inter-brand competition. Theoretical contributions, managerial implications, and future research directions emanating from our research are highlighted.
\end{abstract}

